\title{
“Cimento e lágrimas": objetivações e subjetivações da memória e do trabalho na construção civil habitacional em Vitória da Conquista - BA
}

\section{"Cement and tears": objectifications and subjectivities of memory and work in civil construction in Vitória da Conquista - BA}

\section{"Cemento y lágrimas": objetivaciones y subjetividades de la memoria y el trabajo en la construcción civil en Vitória da Conquista - BA}

Miriam Cléa Coelho Almeida ${ }^{1}$ https://orcid.org/0000-0002-2662-4466

\footnotetext{
1 Doutora, Universidade estadual do Sudoeste da Bahia (UESB), Vitória da Conquista, Bahia-Brasil. Professora Adjunto do Departamento de Geografia, Área de Geografia Humana. miriam.coelho@uesb.edu.br.
}

Recebido em: 27/08/2020 Aceito para publicação em: 30/09/2020

\section{Resumo}

O presente artigo analisa as objetivações e subjetivações da memória e do trabalho na construção civil habitacional em Vitória da Conquista-BA. Para tanto, evidencia as condições objetivas e subjetivas que determinam a constituição e o uso da força de trabalho e que ora reafirmam, ora forçam rupturas na relação contraditória capital-trabalho. Desse modo, ancora-se nos ensinamentos de Marx (1985-2010), Harvey (19822000), Pollak (1989), Hobsbawm (2008), Mészaros (2002-2005), entre outros que se debruçam sobre o trabalho e a memória. A análise dos dados e das narrativas permitiu entrever as transformações ocorridas no processo de trabalho na construção civil habitacional e conhecer as permanências e as rupturas.

Palavras-chave: Trabalho. Memória. Construção Civil.

\begin{abstract}
This article analyzes the objectivations and subjectivities of memory and work in civil construction in Vitória da Conquista-BA. To this end, it highlights the objective and subjective conditions that determine the constitution and use of the workforce, and which, at times, reaffirm, at times force ruptures in the contradictory capital-labor relationship. Thus, it is anchored in the teachings of Marx (1985-2010), Harvey (1982-2000), Pollak (1989), Hobsbawm (2008), Mészaros (2002-2005), among others that focus on work and memory. The data analysis and narratives allowed us to glimpse the changes that occurred in the work process in the housing civil construction and to know the permanences and ruptures.
\end{abstract}

Keywords: Work. Memory. Civil Construction. 


\section{esumen}

Este artículo analiza las objetivaciones y subjetividades de la memoria y el trabajo en la construcción civil en Vitória da Conquista-BA. Para ello, destaca las condiciones objetivas y subjetivas que determinan la constitución y el uso de la fuerza de trabajo, y que, a veces, reafirman, a veces obligan a rupturas en la relación contradictoria capital-trabajo. Así, se ancla en las enseñanzas de Marx (1985-2010), Harvey (1982-2000), Pollak (1989), Hobsbawm (2008), Mészaros (2002-2005), entre otros que se centran en el trabajo y la memoria. El análisis de los datos y narrativas permitió vislumbrar los cambios que se produjeron en el proceso de trabajo en la construcción de viviendas y conocer las permanencias y rupturas.

Palabras clave: Trabajo. Memoria. Construcción Civil.

\section{Introdução}

O presente artigo resulta de pesquisa de doutoramento sobre as memórias do trabalho na construção civil habitacional e suas relações com a produção territorial na cidade de Vitória da Conquista - BA (ALMEIDA, 2017); cumpre a finalidade de analisar as objetivações e as subjetivações decorrentes das transformações do processo de trabalho na construção civil habitacional ao longo dos contextos históricos, tendo como base empírica o processo de trabalho na construção civil habitacional em Vitória da Conquista. Como uma unidade dialética contraditória, o processo de objetivação-subjetivação (MARX, 1985-2010) é evidenciado para se conhecer as determinações na constituição e no uso da força de trabalho e as bases de exploração e dominação dos trabalhadores - impostas pela acumulação flexível com o uso de uma memória reificadora e desumana - e que garantem as condições, por um lado, para a reprodução ampliada do capital e, por outro, para a reprodução da força de trabalho.

Embora as determinações na constituição e no uso da força de trabalho na construção civil habitacional se relacionem com os desdobramentos das formas flexíveis, optou-se por, num primeiro momento, esboçar as determinações que, tradicionalmente, marcaram a constituição e o uso da força de trabalho na construção civil habitacional para, em seguida, tratar das transformações decorrentes de sua incorporação nas formas flexíveis de trabalho nesse setor.

Para esse intento, utilizou-se, sobretudo, da pesquisa direta com os trabalhadores nos espaços de realização do trabalho e da vida. Desse modo, a rememoração de trabalhadores e empresários de suas trajetórias de trabalho e de vida na construção civil habitacional foi fundamental para a produção de dados e narrativas e para estabelecer os nexos entre as memórias e o processo de trabalho. 
Embora a apresentação dos dados permita conhecer algumas especificidades do trabalho assalariado e do trabalho autônomo, partiu-se do princípio de que estes estão, igualmente, inseridos no processo de reprodução ampliada do capital.

\section{As determinações na constituição e no uso da força de trabalho}

Ao mapear o local de nascimento e de moradia dos trabalhadores e analisar as narrativas dos entrevistados, em grande medida, a força de trabalho empregada na construção civil habitacional resulta de processos migratórios ocorridos no Brasil, desde a década de 1960, determinados pelo modelo de "desenvolvimento desigual e combinado" do capital pelo território. Mesmo que outros movimentos possam ser notados, é o movimento do campo para as cidades, em decorrência da expulsão camponesa, que marcou e ainda marca, profundamente, a memória e o trabalho na construção civil habitacional, pois cria o "exército de reserva" que irá constituir a força de trabalho móvel necessária à acumulação capitalista.

Em geral, esses trabalhadores expropriados dos meios de produção e sem alternativas que garantam a sobrevivência partem para a cidade e se sujeitam a um trabalho precário e inumano que, ao mesmo tempo em que lhes garante a sobrevivência, ameaça a sua existência.

Nessas condições de subordinação e assujeitamento, o uso dessa força de trabalho é compreendido por Gaudemar (1977, pp. 193-194).) como o "[...] momento da submissão da mobilidade do trabalhador às exigências do capital. Ela deve prestar-se às formas e transformações da organização do processo de trabalho"

Nessas circunstâncias, os trabalhadores estão prontos para aceitar as condições de trabalho que lhes forem oferecidas e, como logo se verá, submeterem-se às mais variadas formas de exploração e precarização nos canteiros de obras, pois se encontram prontos para serem usados pelo capital na forma que melhor convier aos interesses deste.

Assim, a constituição da força de trabalho na construção civil habitacional se faz por meio da subordinação do trabalho ao capital, que transforma o trabalhador em uma "coisa" ou mero "fator de produção". Além disso, é-lhe imposta uma rigorosa adaptação e obediência a uma disciplina de trabalho a que não estava acostumado; é "forjado a ferro e fogo". Para Harvey (1982, p. 21)), “A imposição de uma disciplina de trabalho foi conseguida em parte através de treinamento, ameaças, incentivos ou bajulações, no local de trabalho". Braverman (1987, p. 68).) salienta o papel do gerente no adestramento dos trabalhadores para controle absoluto dos corpos: "Como um cavaleiro que utiliza rédeas, bridão, esporas, cenouras, chicote 
e adestramento desde o nascimento para impor a sua vontade ao animal, o capitalista empenhase, através da gerência (management), em controlar"

Entre as determinações no uso da força de trabalho na construção civil habitacional em Vitória da Conquista, destacam-se: aquelas relacionadas ao gênero, objetivadas na predominância do trabalho masculino nos canteiros de obras e no papel reservado às mulheres no espaço de reprodução dessa força de trabalho; ao acesso ao conhecimento pelos trabalhadores, cujas trajetórias educativas são utilizadas como mecanismo de acumulação capitalista; às questões etárias com a seletividade das empresas no uso e descarte de jovens e idosos; à venda da mercadoria força de trabalho como única estratégia de sobrevivência e cujo salário é incompatível com o custo de vida; à extensa jornada de trabalho e à extração da mais valia absoluta; e à falta de segurança que coloca a vida dos trabalhadores em risco permanente.

\section{Homens ao trabalho?}

A construção civil habitacional em Vitória da Conquista consome uma força de trabalho, majoritariamente, masculina. Apesar disso, nos canteiros de obras é possível ver o trabalho feminino na realização de atividades de acabamento, como assentamento de cerâmicas, pinturas e limpeza em geral. Registra-se ainda a participação das mulheres em espaços destinados a refeitórios para preparação de alimentos e na higienização das instalações sanitárias. A força de trabalho feminina na construção civil habitacional ainda é pouco expressiva na realidade conquistense. Entretanto, sabe-se de ações para estimular a ampliação, como a realização de palestras e cursos profissionalizantes oferecidos pelo Serviço Brasileiro de Apoio às Micro e Pequenas Empresas (SEBRAE), pelo Serviço Nacional de Aprendizagem Comercial (SENAC), pelo Serviço Social da Indústria (SESI), entre outros. Mesmo com essa motivação, $100 \%$ dos trabalhadores entrevistados, tanto entre os assalariados, quanto entre os autônomos, eram do sexo masculino.

Essa fraca inserção das mulheres é também atestada pelo Censo do IBGE (2010): mesmo com a expansão do setor, dos 11.323 postos, 11.131 eram ocupados por homens e 183, por mulheres. Embora não tenha sido objeto de investigação da pesquisa, acredita-se que o uso de intensa força física e os riscos físicos que, tradicionalmente, acompanham essa atividade devam ser considerados para justificar esse quadro.

Ademais, esse setor econômico sempre foi o destino de migrantes que, em sua maioria, deixavam a esposa e filhos nos lugares de origem e partiam para garantir o sustento da família. 
Esse comportamento leva a destacar o papel da mulher na criação das condições para a reprodução da força de trabalho na construção civil habitacional, pois, embora não estejam majoritariamente presentes nos canteiros de obras, desempenham uma função importante na constituição da força de trabalho masculina.

Trajetória educativa da força de trabalho como mecanismo de acumulação capitalista

Historicamente, a construção civil caracteriza-se pelo intenso uso da força de trabalho, e, para essa atividade econômica, marcham muitos trabalhadores em geral precarizados e com baixo nível de escolarização. Esse setor é marcado pela absorção de grande parte dos trabalhadores desempregados.

A pesquisa direta com trabalhadores assalariados e autônomos da construção civil habitacional mostra que, em Vitória da Conquista, essa realidade não é diferente. A construção civil habitacional tem sido o destino de muitos trabalhadores de origem camponesa, com pouca ou nenhuma escolaridade e precarizados, seja das áreas rurais do próprio município, seja de outros municípios do Sudoeste baiano. Ao particularizar esse quadro tendo como base os trabalhadores assalariados e autônomos entrevistados na sede municipal em 2015 e tendo a escolaridade como foco, nota-se que, em sua maioria, 66\% não ultrapassam o Ensino Fundamental. Destes, apenas 28\% concluíram o Ensino Fundamental, e $72 \%$ abandonaram os estudos nos primeiros anos dessa etapa de ensino. Apenas 13\% concluíram o Ensino Médio, e $20 \%$ o abandonaram. Somente 1\% encontra-se cursando o Ensino Superior. Ao se desagrupar esses dados, percebe-se que, entre os autônomos, encontram-se taxas maiores com menor escolarização e, entre os assalariados, uma discreta ampliação da escolarização até a conclusão do Ensino Médio.

Apesar da presença de uma pequena parcela de trabalhadores com maior nível de escolaridade, a exemplo de engenheiros, arquitetos, entre outros, a construção civil habitacional abriga um volume intenso de força de trabalho cuja formação resulta do processo de "sucessão hereditária", muito comum nessa atividade, como analisa Hobsbawm (2008). Entretanto, vê-se na atualidade uma tendência de enfraquecimento dessa sucessão diante das dificuldades enfrentadas pelos trabalhadores. Esse pedreiro, mesmo tendo aprendido com o pai, ao ser perguntado se ensinaria ao filho a profissão, respondeu:

Claro que não! Quero que meu filho estude pra ser uma pessoa melhor, né? Eu já falei pra ele: - meu filho, cê estuda, porque o trabalho que eu trabalho não é um trabalho pra você. Exige muito esforço, a gente trabalha muito não tem hora de parar, então, você estuda porque esse trabalho não é pra você. O que 
não me agrada não quero pra você. Eu quero que você se sinta bem, que estuda. Isso é um recado que mando pra meu filho e sempre converso com ele: - Pai, estuda muito, dedica, porque senão... Se ele entrar nessa vida que eu tô, não adianta (informação verbal) ${ }^{2}$ (Grifo nosso).

Em geral, supõe-se que a formação decorrente da "sucessão hereditária" explica as razões pelas quais os trabalhadores entrevistados, com baixa escolaridade ou que nunca participaram de cursos profissionalizantes, afirmaram ter aprendido a profissão observando, praticando, fazendo ou seguindo as orientações de um mestre. Na memória dos trabalhadores, esse processo é muito bem marcado. Ao ser perguntado sobre como aprendeu a profissão, um mestre de obra, ao rememorar as primeiras experiências, narrou:

Escola não foi... . Aprendi, praticamente por mim mesmo. $E$ da ajuda as vêis de um pedreiro, por exemplo, que ele me ensinou, foi me ajudando, pegando na culé, aí... tá, tá, vai que eu tô gostando de você (refere-se à fala do mestre de obras) ... e foi assim e aí fui rompeno... Aí, eu fui me soltando sozim, aí eu deixei de trabaiá mais com o mestre de obras, e comecei a trabaiá mais sozim por minha conta...

Eu não tenho diploma de mestre de obra não, eu tenho só prática, agora aprendi tudo com pessoas que sabiam trabalhar e tinham gosto de ensina (informação verbal) ${ }^{3}$ (Grifos nossos).

Essa fala expressa bem a predominância do aprendizado tácito ${ }^{4}$ ou prático na construção civil. Sobre isso, Martins avalia que, para muitos trabalhadores de origem camponesa, a escolarização ocorreu em concomitância com o trabalho e, nesses termos, “[...] assume, por outro lado, um caráter geral na experiência de vida dos que tiveram acesso à escola, independentemente de distinções fundamentais como a que se poderia fazer entre proprietários e não-proprietários, pequenos e grandes proprietários [...]” (MARTINS,1975, p. 87).

Ficam evidentes na trajetória educativa dessa força de trabalho os contornos de um aprendizado tácito, de ofício transmitido de geração a geração. Ademais, são provas incontestáveis de uma memória que se (re) constrói nas experiências no e pelo trabalho.

Essa forma de aprendizado e de construção da memória aparece bem assinalada na história de trabalho desse outro trabalhador:

Começar mesmo, começou em 1972. Fui pra São Paulo, eu já sabia levantar casa, mas não sabia fazer uma casa.... Eu fazia alicerce ainda de pedra, não fazia viga, não fazia nada, daí fui prá São Paulo, daí lá entrei numa firma, fui trabalhar com

\footnotetext{
${ }^{2}$ Entrevista concedida em 20/02/2015.

${ }^{3}$ Entrevista concedida por um mestre de obra. Entrevista gravada por Miriam Cléa Coelho Almeida em 01/11/2014. A grafia foi mantida conforme a fala dos trabalhadores.

${ }^{4}$ Entende-se como aprendizado tácito aquele resultante das experiências no trabalho e na prática cotidiana.
} 
engenheiro, um engenheiro da firma e um mestre de obra, um cabra legal demais! Ele (o mestre) tinha gosto de ensinar uma pessoa trabalhar, ele tinha gosto mesmo. Entrava um cara que não sabia trabalhar, ele encostava, ele mandava, ele pegava um cara mais experiente e falava: "oh, ensina essa pessoa aí que ele não sabe. Ensina aí, vamo fazer dele um pedreiro.”. Era assim [...] Chamava até Orlando, aí eu fui aprendendo trabalhar, e ele me pegava, passava a pranta e ele falava: "olha a pranta! É assim, oia como é que é, assim, assim, assim [...] aprenda" (informação verbal) ${ }^{5}$ (Grifos nossos).

É curioso constatar, nessa narrativa, que essa forma de aprendizado não fica restrita ao trabalho autônomo; ela é levada para o interior das empresas ou firmas, como objetividade ou subjetividade do trabalhador, e, mais tarde, incorpora-se ao conhecimento técnico-científico da educação profissional.

Nas diversas formas que a organização do trabalho assumiu no mundo capitalista desde a manufatura, as experiências originais sempre estiveram presentes, demarcando um caráter de subordinação e de resistência do homem ao trabalho, a exemplo das práticas que dividiram as formas artesanais de produção, evidenciadas na evolução do processo histórico de expropriação gradativa do trabalhador dos instrumentos de trabalho pela divisão social do trabalho. A permanência de práticas tradicionais nos processos de trabalho submetidos à acumulação flexível é também indício de sobrevivência da memória no interior do trabalho, mesmo que as condições não lhe sejam favoráveis.

Entretanto, esse processo não acontece sem conflitos, mesmo no interior de uma mesma classe. Nas declarações desse mestre de obras, estão sinalizados os embates entre os trabalhadores com formações diferentes nos canteiros de obras:

O engenheiro sabe assentar cerâmica? Não sabe. Ele sabe depois de assentada é se tá boa, se tá reta, se tá toda linheira, se não tem diferença nenhuma [...] Aí é que eu digo, quem assenta cerâmica não é o engenheiro, nem nada... Tem que ter prática. Ele (o pedreiro) começou a assentar cerâmica, tem inteligência e, aí, com a prática, ele faz o serviço todo certinho...(Informação verbal) ${ }^{6}$ (Grifos nossos).

É possível perceber o orgulho com o conhecimento tácito, quando confrontado com o trabalho do engenheiro, mas, também, a admissão da inseparabilidade entre teoria e prática, ao admitir, conforme o destaque no relato, que “[...] tem inteligência e, aí, com a prática, ele faz o serviço todo certinho"(informação verbal) ${ }^{7}$. Em outra perspectiva, esse conflito demonstrado na declaração do mestre de obras tem sido constante nos canteiros de obras, sobretudo em

\footnotetext{
${ }_{6}^{5}$ Entrevista concedida em 01/11/2014 por um mestre de obra. A grafia foi mantida conforme a fala dos trabalhadores.

${ }^{6}$ Entrevista concedida por um mestre de obra. Entrevista gravada por Miriam Cléa Coelho Almeida em 01/11/2014

${ }^{7}$ Idem
} 
decorrência da divisão do trabalho na construção civil habitacional, agudizada pelas demandas da "acumulação flexível” (HARVEY, 2000).

Essas situações de enfrentamento são justificadas por Kuenzer (2003, p. 48), ao avaliar que "[...] as formas históricas de organização e gestão da força de trabalho com vistas à realização da acumulação não se superam por substituição, mas sim por incorporação [...]" (Grifo nosso).

Isso explica porque a baixa escolaridade dos trabalhadores, por um lado, aprofunda a separação do trabalho em manual e intelectual e, por outro, contraditoriamente, também os aproxima na medida em que se constitui em um mecanismo de acumulação. Por isso, na construção civil habitacional, há trabalhadores que apenas pensam, planejam (arquitetos e engenheiros), que apenas executam, passivamente, os projetos (demais trabalhadores), mas também não é incomum encontrar aqueles que combinam o conhecimento tácito com o conhecimento científico, a exemplo de pedreiros ou mestres de obra que realizam funções do engenheiro e arquitetos, no planejamento e na execução das obras, como estratégia de maximização dos lucros por meio da exploração, precarização e barateamento da força de trabalho.

Além disso, considera-se ainda que a inserção das demandas da acumulação flexível no processo de trabalho, na construção civil habitacional, não faz desaparecer a memória do conhecimento tácito; ao contrário, na avaliação de Kuenzer (2003, p. 52), “[...] se reestabelece a dialética entre teoria e prática, passando a competência a assumir dimensão práxica [...]”. Desse modo, a atividade prática requer o uso, tanto do trabalho material, quanto do não material, e a atividade intelectual não se realiza fora da prática ao produzir ideias, conceitos e representações.

Outro aspecto a ser mencionado é que, mesmo com a baixa escolaridade apresentada entre os trabalhadores, houve pouca manifestação de vontade de dar continuidade aos estudos. Somente entre os trabalhadores assalariados, ela foi apontada. Na avaliação de Kuenzer (1995, p. 47), a fraca procura pela ampliação da formação ocorre porque os trabalhadores estão reduzidos à condição de mercadoria força de trabalho; assim, o operário "[...] emprega todo o seu tempo disponível a serviço da reprodução ampliada do capital [...]”, e, dessa forma, não dispõe de tempo para realização de outras atividades ligadas a educação, lazer, descanso, entre outras.

Assim, o desejo de ampliação da formação está, quase sempre, associado à garantia de manutenção nos postos de trabalho e à possibilidade de subir na hierarquia da empresa. 
Aproximadamente $40 \%$ dos trabalhadores assalariados almejam mudar de função na empresa. Acredita-se que esse desejo de alcançar funções mais especializadas e com maior rendimento salarial nos canteiros de obra é o que justifica a busca e a subordinação do trabalhador a uma educação profissional voltada para o atendimento das exigências impostas pelo capital, mas, ao mesmo tempo, constitui-se numa estratégia dos trabalhadores de sobrevivência no mercado de trabalho. Nesse sentido, os cursos técnicos oferecidos são a única possibilidade de ampliação da formação que os trabalhadores declararam ter acesso, os quais apenas reforçam as estratégias de formação da força de trabalho em prol do capital.

Entre os trabalhadores assalariados entrevistados, 39\% declararam já ter participado de algum curso profissionalizante que, em geral, são cursos técnicos de curta duração. Entre estes, $33 \%$ assumiram os custos com o curso, $47 \%$ tiveram os cursos oferecidos pelas construtoras em que trabalhavam, e $20 \%$ procuraram cursos gratuitos ministrados por instituições, que disponibilizam cursos profissionalizantes a exemplo do SESI, ou empresas específicas de revenda de materiais de construção. Quanto ao tempo de duração desses cursos, embora os trabalhadores não soubessem precisar em horas, indicaram o tempo em dias, semanas, meses ou anos em que participaram das atividades, o que possibilitou chegar a uma carga horária aproximada. Assim, 27\% são cursos de 6 a 12 horas (geralmente oferecidos pelas empresas, no próprio local de trabalho e, quase sempre, tratam de cursos práticos para habilitação do trabalhador no uso de algum tipo de material ou equipamento na construção civil); $20 \%$ são cursos de 40 horas (normalmente utilizam a semana inteira e têm as mesmas características do anterior ou se trata da habilitação de algum trabalhador específico, como o servente "orelha seca" para a condição de "servente prático", ou ainda, visam capacitar os trabalhadores para as técnicas de segurança, organização de material para evitar desperdícios no canteiro de obras, entre outros temas abordados por esses cursos); 47\% são cursos acima de 100 horas (estão relacionados a cursos por correspondência para alguma habilitação em mecânica, elétrica, hidráulica, entre outros), $6 \%$ dos trabalhadores afirmaram ter participado de cursos com dois anos de duração e fizeram referência a cursos de técnicas de edificação.

Esse cenário corrobora a tese defendida por Frigotto, Ciavatta e Ramos (2014, p. 67) de que "[...] a política de educação profissional [...] de fato tem ampliado a formação de trabalhadores [...], porém, para o trabalho simples, o "trabalho barato"”. Ou, como assegura Kuenzer (2003, p. 47). a relação entre trabalho e educação, conforme os princípios da acumulação flexível, expressa-se por “[...] um sistema de educação e formação profissional que

\footnotetext{
${ }^{8}$ Essa denominação é dada aos trabalhadores que desempenham a função de servente e que não possuem nenhuma experiência anterior.
} 
inclui para excluir ao longo do processo, seja pela expulsão ou pela precarização dos processos pedagógicos que conduzem a uma certificação desqualificada"

Em geral, a trajetória educativa dos trabalhadores da construção civil no Brasil é marcada pela "sucessão hereditária", por meio do conhecimento tácito, mas, também, encontrase consolidada a educação profissional, cuja finalidade é a habilitação técnica, social e ideológica do trabalhador para o mercado. Daí deriva o contraste entre o volume intenso de uma força de trabalho com baixa ou nenhuma escolarização, principalmente no desempenho de funções pouco qualificadas e com menor remuneração, e os poucos trabalhadores com níveis médio e superior de ensino em postos de alta qualificação e remuneração.

Apesar desse contraste, a baixa ou nenhuma escolarização de grande parte dos trabalhadores, associada à intensa divisão do trabalho, constitui-se em estratégias para a obtenção do lucro, sendo, portanto, muito úteis na extração de mais valia em sua forma absoluta. Diante disso, a baixa escolaridade não tem sido um problema para a expansão da produtividade e lucratividade na construção civil; ao contrário, ainda se constitui em uma vantagem no que se refere à redução dos custos com a contratação da força de trabalho e, portanto, um instrumento para a acumulação. Essa estratégia tem sido considerada, por alguns pesquisadores, como mais vantajosa que a inserção tecnológica no setor.

Essa realidade requer que se pense o analfabetismo e a baixa escolaridade dos trabalhadores para além da naturalização desses processos, mas como produto capitalista na exploração da força de trabalho ou na ampliação do exército de reserva. Nessa direção, não se constituiriam num problema a ser enfrentado, mas expressariam a lógica da acumulação capitalista, pois, como se demonstrou, o consumo intenso de uma força de trabalho pouco qualificada e precária na construção civil habitacional continua sendo uma forma eficiente para sua ampliação.

\section{Uso e descarte da força de trabalho jovem e idosa: uma ameaça à memória?}

A composição da força de trabalho por idade, na construção civil habitacional, também dá indícios de relação com os mecanismos de acumulação. Ao examinar a estrutura etária dos trabalhadores entrevistados assalariados e autônomos, numa variação da idade entre 16 e mais de 50 anos, registra-se uma concentração dos trabalhadores, 76\%, no intervalo de 25 a 49 anos. Entre 16 e 24 anos, observa-se uma pequena presença de trabalhadores e, após os 50 anos de idade, verifica-se uma forte queda. Ao se desagrupar esses dados, no trabalho assalariado vê-se 
que esse comportamento é mais evidente. Entre os autônomos, embora siga a mesma tendência de concentração, chama a atenção o fato de os trabalhadores com mais de 50 anos constituírem maior percentual em relação aos assalariados.

Em geral, o comportamento dos dados indica, em princípio, duas tendências: a retração nos postos de trabalho de jovens com idade menor que 20 anos e a queda após os 40 anos. Ao analisar a participação de jovens e idosos no mundo do trabalho, Antunes (2003 p. 56-57). também destaca esse aspecto:

Outra tendência presente no mundo do trabalho é a crescente exclusão dos jovens, que atingiram a idade de ingresso no mercado de trabalho e que, sem perspectiva de emprego, acabam muitas vezes engrossando as fileiras dos trabalhos precários e dos desempregados, dada a vigência da sociedade do desemprego estrutural. Paralelamente à exclusão dos jovens, vem ocorrendo a exclusão dos trabalhadores considerados "idosos" pelo capital, com idade próxima de 40 anos e que, uma vez excluídos do trabalho, dificilmente conseguem reingressar no mercado de trabalho

A análise dessas tendências não pode desconsiderar a crise estrutural do capital, o crescimento do exército de reserva e a produção do desemprego, que negam a possibilidade de inserção no mercado de trabalho para muitos jovens - quando muito, são inseridos pelos mecanismos de acumulação flexível nas formas de contratação da força de trabalho barata, a exemplo dos estágios, menores aprendizes, entre outras, cujo objetivo é o aumento da produtividade e da lucratividade.

Essas determinações, articuladas com as características atuais da construção civil habitacional, como o trabalho exaustivo com forte emprego da força física e a exposição a riscos de acidentes, fazem com que a "vida útil" dos trabalhadores para o capital seja ainda muito curta, principalmente pedreiros e serventes, que, quase sempre, realizam trabalhos mais pesados e se expõem a maiores riscos.

Entre os trabalhadores assalariados, o descarte é ainda maior, sobretudo quando não dispõem das condições físicas para suportar o trabalho pesado e a rigidez do tempo produtivo dos canteiros de obra. Essa realidade explica o fato de muitos trabalhadores com idade superior a 50 anos optarem pelo trabalho autônomo.

Ao avaliar essa realidade objetiva com a construção e sobrevivência da memória, o descarte dos trabalhadores com mais tempo de trabalho pode significar uma ruptura ou uma "perda de memória" do trabalho, na medida em que eles seriam os "guardiões" das "tradições fixas do ofício" e, portanto, responsáveis pela transmissão de uma geração a outra. 
Venda da mercadoria força de trabalho e os baixos salários

Com as determinações apresentadas, os trabalhadores, transformados em mercadoria e subjugados ao capital, não dispõem de alternativa que não a venda daquilo que lhe resta: a força de trabalho a qualquer custo e para qualquer trabalho, como estratégia de sobrevivência.

Diante disso, ao se levantar a remuneração mensal declarada pela totalidade dos trabalhadores entrevistados, viu-se que a maioria dos trabalhadores (51\%) percebe entre 1 e 2 salários mínimos; $12 \%$ têm salário inferior ao salário mínimo, o caso dos estagiários; 8\%, apenas um salário mínimo; 23\%, entre 2 e 3 salários mínimos; $5 \%$ tem rendimento superior a 3 salários mínimos; e $1 \%$ não respondeu. Ao comparar a remuneração entre os assalariados e autônomos, não se observa grande diferença, embora a remuneração dos assalariados tenha uma concentração maior entre 1 e 3 salários mínimos e, no trabalho autônomo, mais trabalhadores recebam menos de 1 salário mínimo mensal. Os valores relativos à remuneração mensal dos trabalhadores assalariados são o somatório do salário base, com gratificações, auxílios e adicionais definidos na Convenção Coletiva dos trabalhadores da categoria evidenciados mais adiante.

Considerando o fato de que $73 \%$ dos trabalhadores entrevistados declararem ter de sustentar família com filhos, conclui-se que esses rendimentos não são suficientes para suprir as necessidades básicas, o que tem justificado a complementação da renda mensal com outras atividades no turno oposto, como se mencionou. A incompatibilidade entre o valor dos salários e os custos de vida dos trabalhadores impõe uma luta, tanto no interior do trabalho, quanto fora dele, para garantir a sobrevivência.

No interior do trabalho, a luta se faz por meio da reinvindicação de aumento salarial e do cumprimento de direitos trabalhistas conquistados no embate com as empresas. A luta fora do trabalho se dá contra a propriedade privada e o monopólio da terra no espaço urbano.

A composição dos rendimentos dos trabalhadores assalariados é definida pelos pisos normativos aprovados em Convenção Coletiva dos trabalhadores e praticada pelas empresas da construção civil localizadas no interior do estado da Bahia. A Convenção Coletiva de Trabalho celebrada entre o Sindicato da Indústria da Construção do Estado da Bahia (SINDUSCON) e o Sindicato dos Trabalhadores na Indústria da Construção e da Madeira no Estado da Bahia 
$(\text { SINTRACOM })^{9}$ define 33 especializações como operários qualificados, desde que possuam experiência mínima de seis meses no exercício da profissão, comprovada pela Carteira de Trabalho Profissional ou por certificados emitidos pelo Serviço Nacional de Aprendizagem Industrial (SENAI) ou outros órgãos. Esse volume de especializações dos trabalhadores somado às oito funções não qualificadas atesta o esfacelamento do trabalho e dos trabalhadores na construção civil e mostra a realização de uma divisão do trabalho ao seu limite máximo.

O quadro geral dos pisos normativos básicos em vigência (de 01/01/2019 a 31/12/2020) indica como menor piso o dos serventes comuns $\mathrm{R} \$ 1.024,14 \mathrm{e}$, como maior piso, o do encarregado, no valor de $\mathrm{R} \$ 2.668,74$. Isso confirma que os serventes, apesar de realizarem as tarefas mais pesadas, são os que recebem menor piso salarial. Essa realidade mostra o uso da mais valia absoluta ainda hoje como mecanismo de acumulação. Se tomarmos o salário do pedreiro, considerado operário qualificado pela Convenção (2019/2020) no valor de R\$ $1.734,21$, a sua diária de trabalho é de, aproximadamente, $\mathrm{R} \$ 57,80$, considerada muito baixa pelos trabalhadores. Por isso, as insatisfações são muitas, e o desabafo desse trabalhador ganha sentido:

Eu sempre falo, eu acho que o pedreiro devia ser bem remunerado, porque, quando você chega num lugar, numa cidade e cê acha a cidade bonita, os préidos bonito e tudo, quem foi que fez? Foi o pedreiro. O engenheiro fez a pranta e passou para o pedreiro, o pedreiro foi quem fez tudo... Assim, às vezes um pedreiro mais fraco não sabe fazer a pastilha mas já faz um levantamento, a parte de alvenaria, faz a parte de massa grossa, né, mas foi passado tudo pelo pedreiro (informação verbal). ${ }^{10}$

Além do piso básico, a Convenção estabelece gratificações, adicionais, auxílios, entre outros, como Pagamento de Horas-Extras, Adicional Noturno, Insalubridade e Periculosidade, Prêmio Aposentadoria, Alimentação, Cesta Básica, Transporte, Seguro em Grupo de Acidente de Trabalho, Auxílio Funeral, Auxílio para Assistência a Filho Excepcional, Auxílio Creche e Convênio Farmácia.

Quanto aos serventes práticos, estes são identificados como “[...] Empregados que auxiliam diretamente os Operários Qualificados, desde que executem essas tarefas durante mais de seis meses na mesma empresa, ou que tenham comprovação na carteira profissional, ou aprovados em teste prático realizado na empresa"(informação verbal) ${ }^{11}$.

\footnotetext{
9 Convenção Coletiva de Trabalho celebrada entre SINDUSCOM e SITRACOM (2019/2020), disponível em: http://sintracom.org.br/2016/wp-content/uploads/2019/04/conv-coletiva-constr-sintra-2019-2020.pdf

${ }^{10}$ Entrevista concedida por um mestre de obra. Entrevista gravada por Miriam Cléa Coelho Almeida em 01/11/2014

11 Convenção Coletiva de Trabalho celebrada entre SINDUSCOM e SITRACOM (2019/2020), disponível em: http://sintracom.org.br/2016/wp-content/uploads/2019/04/conv-coletiva-constr-sintra-2019-2020.pdf
} 
É nesse trabalho fragmentado, com remunerações e relações trabalhistas distintas, que se estabelece a hierarquia, fundam-se o poder e o conflito entre os trabalhadores assalariados e se facilita a subordinação do trabalho ao capital. Não compõem o quadro de trabalhadores da construção civil os engenheiros e arquitetos, pois são regidos pelo Conselho Regional de Engenharia e Agronomia (CREA - BA).

Já para os trabalhadores autônomos da construção civil habitacional, os rendimentos são variáveis e a definição do valor do trabalho decorre da negociação com os contratantes particulares. Assim, as diárias podem variar de um trabalhador para outro e de uma obra para outra, ou de uma especialização a outra.

No trabalho autônomo, a divisão do trabalho parece se manifestar com menor força, pois é muito comum encontrar profissionais (principalmente pedreiro) que realizam várias funções no canteiro de obras. Apesar das particularidades do trabalho autônomo da construção civil habitacional, ele também é capturado indiretamente pelo capital, na medida em que amplia o consumo de insumos e materiais para uso na construção.

Jornada de trabalho e mais valia absoluta

A pesquisa direta com os trabalhadores foi reveladora da objetividade e subjetividade do trabalho na construção civil habitacional. A maioria absoluta dos trabalhadores assalariados $(87 \%)$ tem uma jornada de trabalho declarada de 8 horas semanais; jornadas maiores são justificadas pelas horas extras na própria empresa (10\%) ou com a extensão da jornada pelo turno noturno e nos finais de semana para complementação de renda familiar mensal. Já entre os trabalhadores autônomos, a jornada de trabalho declarada não é muito diferente. Dos trabalhadores entrevistados, $89 \%$ afirmaram ter uma jornada de trabalho de 40 a 44 horas, e $11 \%$, de 49 horas ou mais.

Alguns trabalhadores assalariados ou autônomos declararam que a extensão da jornada de trabalho para o final de semana depende da oferta de serviços e não hesitam em abrir mão do descanso para realizar pequenas obras, geralmente domiciliares, para complementação da renda familiar mensal. Esse comportamento é sintomático dos baixos rendimentos dos trabalhadores na construção civil habitacional e da incompatibilidade com o custo de vida, pois $60 \%$ dos trabalhadores entrevistados constituem família, e $73 \%$ possuem prole, fato que agrava as condições de existência.

Desse modo, seja na empresa, seja em outros serviços complementares, a ampliação da jornada de trabalho é a alternativa encontrada para equilibrar o orçamento familiar e garantir a sobrevivência. $\mathrm{O}$ trabalhador dedica todo o tempo à reprodução do capital como estratégia de 
sobrevivência que, contraditoriamente, ameaça sua existência. Como já sinalizado em Gaudemar (1977), os trabalhadores nessas condições ou vendem a força de trabalho, ou morrem.

\section{A vida em risco nos canteiros de obra}

A construção civil tradicionalmente é um setor em que os riscos de acidentes são frequentes. Atualmente, apesar de maior fiscalização e controle das empresas quanto ao uso dos equipamentos de segurança, por ser uma exigência da legislação trabalhista, ainda são registrados acidentes de trabalho. Entre os trabalhadores entrevistados, 13\% declararam já terem sido vítimas de acidentes. Desse total, 64\% trabalham como autônomos, e 36\%, como assalariados. No elenco de acidentes mencionados, os principais são quedas (de andaime, telhados ou prédios), cortes nos membros superiores e choques elétricos.

No trabalho autônomo, observa-se uma incidência maior de acidentes, talvez pelo fato de, na condição de autônomo, não haver maior fiscalização quanto à cessão dos equipamentos pelos contratantes e ao uso pelos trabalhadores. A fala de um mestre de obras destaca essa situação:

Geralmente eu não peço o dono do trabai não, né? Como é eu mesmo, as vêis eu trabalhando com o ajudante o que precisa eu compro... As vêis uma luva mesmo eu compro, né? Ferramenta eu compro, né? Eu não exijo também, não, na diária assim, por exemplo, né? Eu levo minhas ferramentas tudo, o que precisa eu levo... Se precisar de capacete, eu levo, bota eu levo, né? Prá não tá exigindo muito das pessoas, pois é né?...(risos) (informação verbal) ${ }^{12}$ (Grifos nossos).

Muitas vezes, os contratos particulares são realizados diretamente com o pedreiro, que é responsável pela contratação da equipe. Assim, nem o contratante nem o pedreiro que subcontratou o serviço assumem os custos com a disponibilização dos equipamentos. Além disso, é justo registrar que, mesmo quando os equipamentos são cedidos pelos contratantes, alguns trabalhadores criam resistência, por considerá-los pouco confortáveis, por falta de hábito, ou ainda, por confiarem em suas habilidades e cuidado.

Essa mensuração dos acidentes, entretanto, pode estar subdimensionada, já que, nas entrevistas com os trabalhadores, percebeu-se receio em tratar dessa questão. Assim, alguns acidentes foram omitidos ou minimizados, pois tais ocorrências atestam contra o trabalhador, ao serem classificados como negligentes ou indisciplinados, o que pode comprometer a

\footnotetext{
${ }^{12}$ Entrevista concedida por um mestre de obra. Entrevista gravada por Miriam Cléa Coelho Almeida em 02/11/2014 
inserção em futuros postos de trabalho. Os trabalhadores minimizaram a gravidade do acidente, ao reconstruírem o passado sob o medo da punição: “Tive uma vez. É, uma vez. [...] Uma vez que eu caí de um andaime. [...] Mas não foi muito grave, também, não. [...] eu fiquei uns treis meis mais ou menos internado" (Grifos nosso) ${ }^{13}$. "Perdi dois dedos, mas não foi nada, não [...] não me atrapalha prumode que eu faço tudo do mermo jeitim [...]" (informação verbal) $\left(\right.$ Grifos nossos) ${ }^{14}$.

Os acidentes impõem um duplo sofrimento: o da lesão física e o do medo de ter a sobrevivência ameaçada. Aí estão, em grande medida, as "razões do silêncio" que, como nos ensina Pollak (1989, p. 5).), “[...] longe de conduzir ao esquecimento, é a resistência que uma sociedade civil impotente opõe ao excesso de discursos oficiais"

Assim, os acidentes, embora pouco visíveis por serem encobertos, ora pela empresa, ora pelo trabalhador, estão lá, compondo a "memória subterrânea" do trabalho na construção civil habitacional, mas que podem aflorar "[...] em momentos de crise em sobressaltos bruscos e exacerbados" (POLLAK, 1989, p. 4). Na construção civil habitacional, esse silêncio vem à tona como bandeira de luta dos sindicatos ou como reclamações jurídicas, principalmente após o rompimento ou encerramento do contrato de trabalho.

\section{Os desdobramentos das formas flexíveis para o trabalho e para os trabalhadores da construção civil habitacional}

A incorporação das formas flexíveis na construção civil habitacional intensifica ou cria processos que desafiam a luta e resistência dos trabalhadores. Entre eles, destaca-se a agudização da divisão do trabalho, que cria condições para implantação de formas de contratação e relações de trabalho, como a terceirização, que, ao aliar as especificidades desse setor econômico, traduz-se em uma intensa rotatividade e informalidade nas contratações da força de trabalho.

Esses processos agravam o estranhamento dos trabalhadores com o processo de trabalho, com o produto, consigo mesmo e entre eles e tornam mais visíveis a hierarquia e o poder nos canteiros de obras, além de dificultar os planos de luta e de resistência.

\section{Agudização da divisão do trabalho na construção civil habitacional}

\footnotetext{
${ }^{13}$ Idem

${ }^{14}$ Entrevista concedida por um mestre de obra. Entrevista gravada por Miriam Cléa Coelho Almeida em 05/11/2014 
A divisão do trabalho na construção civil não é um processo recente; ao contrário, temse manifestado ao longo da história. Constitui-se em um mecanismo poderoso para viabilização das formas exploratórias da acumulação flexível. Afinal, é por meio da divisão do trabalho que se intensifica a subordinação do trabalho da construção civil habitacional ao capital. Isso é responsável por uma série de processos, entre eles a precarização, que se traduz pela terceirização, especialização, informalidade e rotatividade, cujos efeitos são sentidos, entre outros, na perda da autonomia dos trabalhadores, na medida em que se limitam à produção de partes específicas da construção e, com isso, distanciam-se cada vez mais do produto final do trabalho, levando o processo de estranhamento ao extremo, pois, com um trabalho fetichizado e estranhado, fica mais fácil a realização dos planos do capital.

Assim, a fragmentação e a especialização são características marcantes do trabalho na construção civil habitacional. Entretanto, nesse aspecto, uma realidade diferente é percebida entre os trabalhadores assalariados que atuam nas grandes empresas e os trabalhadores autônomos. Enquanto 100\% dos trabalhadores assalariados executam, nas empresas, a mesma função para as quais foram contratados, por força das exigências da empresa ou pela fiscalização trabalhista (com exceção de alguns serventes que, na prática, realizam o serviço do pedreiro, mas recebem uma remuneração relativa ao serviço de servente), os trabalhadores autônomos declararam realizar diferentes funções. Para alguns, isso é motivo de orgulho, pois dão conta de todas as etapas da construção, do alicerce ao telhado, e se autodenominam de "5 em 1" ou "X tudo". Sabe-se, entretanto, que estão sujeitos à maior exploração do trabalho.

Esse mestre de obra lembra com orgulho do tempo em que podia realizar todas as etapas da construção: "Eu fazia tudo! Eu levantava a obra, fazia, aí, a casa, a pessoa olhava assim e falava foi ocê que fez essa casa? Foi. Prédio, a pessoa olhava assim.... não foi você quem levantou esse prédio? E a responsabilidade era minha [...](informação verbal)"15.

Todavia, esse quadro não significa que os trabalhadores assalariados não saibam realizar outras atividades, pois $32 \%$ disseram que realizam outro trabalho no turno noturno para complementação da renda familiar mensal. Em geral, são atividades relativas ao trabalho na construção civil, mas, também, desenvolvem outras funções, como músico, frentista, catador de café, apicultor, vendedor de bijuterias, árbitro de futebol, jardineiro, barman, entre outros "bicos".

Essa característica mostra que a divisão do trabalho, além de produzir um trabalho polissêmico e multifacetado, produz também um trabalhador polivalente e de múltiplas faces.

\footnotetext{
${ }^{15}$ Entrevista concedida por um mestre de obra. Entrevista gravada por Miriam Cléa Coelho Almeida em 01/11/2014 
Desse modo, é muito comum encontrar serventes que são pintores no turno noturno, pedreiros que também são eletricistas ou encanadores em outros serviços no turno oposto, entre outras combinações.

\section{Terceirização e a exploração dos trabalhadores}

As condições materiais dos trabalhadores têm determinado o grau de subordinação às formas de exploração e dominação, tanto nos postos de trabalho oferecidos pelas empresas construtoras, quanto naqueles buscados pelos autônomos, pois, para muitos, representam a luta pela sobrevivência.

Nessa narrativa de um trabalhador, estão as razões para a submissão aos diferentes mecanismos das empresas ou dos contratantes particulares, que objetivam buscar a produtividade e ampliar a lucratividade:

[...] a gente é pai de família, a gente necessita do trabalho, a gente tem que, né? ... Por isso que a gente trabalha, porque a gente precisa! Porque, se não fosse, se tivesse outro meio, a gente não estaria nesse meio mais de serviço de pedreiro. $\mathrm{O}$ único jeito que a gente tem é esse pra poder sobreviver e botar o alimento dentro de casa. Tem hora que nem dá porque o dinheiro não chega nas nossas mãos (informação verbal) ${ }^{16}$.

Além da necessidade de trabalhar para manter a família, a produção do desemprego, como já tratada, tem justificado o avanço da terceirização, que se apresenta como uma resposta capitalista para a crise estrutural e, contraditoriamente, para a redução do desemprego por ele criado.

Se, por um lado, as empresas, mesmo cedendo às determinações do dissídio da categoria, desenvolvem estratégias de redução de custos na contratação da força de trabalho, seja com a terceirização, contratação de estagiários, de menores aprendizes, seja com a realização de um controle absoluto sobre o desempenho dos "corpos" nos canteiros de obra, por meio da vigilância permanente de mestres de obra, encarregados, apontadores, entre outros, por outro, no trabalho autônomo, os pedreiros reclamam do rompimento do contrato pelos particulares, e os serventes reclamam da exploração de pedreiros, que, em muitos casos, também desempenham a função de "gato", pois "pegam" o serviço e são responsáveis pela

\footnotetext{
${ }^{16}$ Entrevista concedida por um trabalhador da construção civil. Entrevista gravada por Miriam Cléa Coelho Almeida em 20/02/2015
}

Geopauta, Vitória da Conquista, ISSN: 2594-5033, V. 4, n.3, 2020, p.(227-254) http://periodicos2.uesb.br/index.php/geo, 
contratação e pagamento da equipe. O mesmo acontece com outros trabalhadores da construção civil habitacional, como eletricista, armador, encanador, pintor, gesseiro, vidraceiro, carpinteiro.

Essa natureza diversa da terceirização é analisada por Alves (2005, p. 79), ao examinar as implicações da reestruturação produtiva no Brasil:

A natureza do processo de terceirização é bastante diferenciada podendo abranger contratos de trabalho domiciliar, contratos de serviços de terceiros (empresas ou individuais) e ainda formação de "cascatas" de subcontratações (empresas contratadas que subcontratam outras empresas)

Ao rememorar uma experiência de trabalho para um "gato" que recrutava trabalhadores para serviço em uma grande empresa, este trabalhador denuncia a natureza perversa da terceirização:

Foi das piores possíveis. Porque eles contrata a gente pra trabalhar e fala que é daqui de Conquista [...] mas quando a gente vai ver eles são de fora. Quando a gente vai falar sobre pagamento, sobre carteira de trabalho ele leva a carteira e fica com a carteira retida 15, 30 dias e quando devolve pra gente é sem fichar a carteira. Aí, a gente fica trabalhando como se fosse autônomo mesmo, e não como fichado. É horrível trabalhar pra gato... Desse jeito... a gente chega lá eles quer que a gente trabalha igual um escravo pra eles, só que no pagamento eles recua, eles não quer chegar nem num acordo com a gente. A gente procura saber como é que tá as coisas, dá carteira de trabalho, eles pega e não dá nenhuma resposta pra gente. A gente fica trabalhando como um escravo pra eles, e eles não dá nenhuma condições de trabalho pra gente trabalhar pra eles. Às vezes nem equipamentos de segurança eles dão pra gente. (informação verbal $)^{17}$

Ademais, nas conversas com os trabalhadores entrevistados fica claro o avanço da terceirização na construção civil habitacional em Vitória da Conquista. A terceirização não mais se limita às grandes empresas, também está presente nas contratações para serviços menores de reformas e ampliações residenciais, por grandes empreiteiros ou pequenas equipes constituídas de um mestre de obras que, em geral, monta a equipe de trabalho para "pegar" o serviço e, quando este extrapola as condições de realização da equipe, faz as subcontratações, nos moldes já demonstrados.

Muitos trabalhadores declararam nem mesmo saber, de fato, para quem estão trabalhando - essa é uma das dificuldades apontadas pelos trabalhadores "para buscarem os seus direitos". E, assim, a terceirização segue em sua cruzada destrutiva contra os trabalhadores.

${ }^{17}$ Idem

Geopauta, Vitória da Conquista, ISSN: 2594-5033, V. 4, n.3, 2020, p.(227-254) http://periodicos2.uesb.br/index.php/geo, 


\section{A rotatividade na contratação da força de trabalho}

Entre os trabalhadores assalariados entrevistados que atuam nas empresas construtoras, $89 \%$ possuem carteira assinada, $8 \%$ são empreiteiros autônomos e 3\% são estagiários com contratos temporários. Entretanto, faz-se uma advertência para o fato de que, na construção civil, conforme relatos de trabalhadores, a contratação formal, às vezes, esconde acordos escusos entre patrão e empregado. Nesses acordos, o trabalhador, sem alternativa, submete-se a aceitar o trabalho formal, mas recebe valor inferior ao registrado na Carteira de Trabalho. Essa prática tem como objetivo burlar a fiscalização trabalhista e isentar a empresa das multas previstas na legislação. Ademais, constitui em mais uma forma de baratear os custos com a mercadoria força de trabalho no processo produtivo.

Outro aspecto a se considerar é que, mesmo que os trabalhadores tenham a carteira assinada, as contratações ocorrem por curtos períodos e, em muitos casos, não ultrapassam um ano; geralmente duram o período de execução da obra. Essa rotatividade é confirmada ao se levantar o tempo de trabalho dos trabalhadores assalariados na mesma empresa: 53\% têm menos de um ano de trabalho; $42 \%$, entre 1 e 5 anos; e apenas $5 \%$ ultrapassam os 6 anos de trabalho nas empresas.

A alta rotatividade dos trabalhadores tem sido uma tendência na construção civil não só no Brasil, mas no mundo inteiro, e encontra as bases no fato de que, no trabalho da construção, em grande medida, os contratos são realizados por obra e obedecem aos prazos estabelecidos para execução, sob pena de pesadas multas. Essas determinações deixam os trabalhadores vulneráveis às demissões em massa e, consequentemente, à procura constante por novas colocações no trabalho formal ou autônomo.

A rotatividade tem sido apontada pelos órgãos de controle de acesso ao Seguro Desemprego como responsável pela alta procura dos trabalhadores por esse benefício e, segundo informações da Secretaria de Desenvolvimento, Trabalho e Renda de Vitória da Conquista, tem provocado distorção na finalidade do benefício, na medida em que os trabalhadores, mesmo no período de vigência do seguro, estão trabalhando como autônomos na construção civil. Conforme avaliação da Secretaria, essa duplicação do rendimento do trabalhador tem descaracterizado a finalidade do seguro, pois, conforme determinações legais, 
no período de vigência do benefício, “[...] o trabalhador [...] não pode receber outra remuneração oriunda de vínculo empregatício formal ou informal"18.

Recentemente houve alteração na Medida Provisória 665/2014, no Art. 3º, Inciso I, Alíneas "a", "b" e "c", que trata dos critérios de habilitação para acesso ao seguro desemprego. Com a alteração, o tempo de trabalho com carteira assinada, para que o trabalhador tenha acesso ao benefício pela primeira vez, subiu de 6 para 18 meses. Na segunda solicitação, esse prazo cai para 12 meses e, a partir da terceira solicitação, cai para 6 meses. A justificativa apresentada pelo governo para realizar as alterações na MP 665/2015 foi eliminar excessos, aumentar a transparência e corrigir distorções para garantir a sustentabilidade dos programas que utilizam o Fundo de Amparo ao Trabalhador (FAT) e o da Previdência Social.

Entretanto, essa alteração atinge bruscamente os trabalhadores da construção civil habitacional que se encontram na situação da primeira solicitação, pois a exigência de 18 meses de salários anteriores para essa solicitação já dificulta, ou mesmo, exclui do benefício muitos trabalhadores da construção. Como visto, na construção civil ocorre forte rotatividade, por força dos contratos por obra ou por curtos períodos, fato que distancia os trabalhadores dessa exigência legal.

\section{A informalidade nas contratações da força de trabalho}

A terceirização e a rotatividade do trabalho na construção civil habitacional potencializam a informalidade das contratações da força de trabalho. A contratação por obra, por empreita, os "contratos de boca" com a promessa de assinatura da carteira e a retenção pelo contratante são estratégias utilizadas para a informalidade das contratações. O curto período das contratações e a demora na formalização do trabalho fazem com que muitos trabalhadores desistam da formalização para não "mancharem a carteira", uma vez que o registro de curtos períodos, na prática, atesta contra a qualidade e competência do próprio trabalhador.

Porém, esse comportamento parece estratégico para as empresas, na medida em que reduz os custos trabalhistas. Uma das razões que levam a esse comportamento dos trabalhadores é a preocupação com as futuras contratações, pois um dos critérios utilizados pelas empresas para a contratação do que consideram como um bom profissional é, exatamente, a longa duração do trabalho em empresas anteriores. Aqui, parece existir um paradoxo: a mesma empresa que utiliza esse critério para a contratação da força de trabalho é a mesma que

\footnotetext{
${ }^{18}$ Extraído de http://portal.mte.gov.br/seg_desemp/seguro-desemprego.htm
} 
faz as contratações por curtos períodos por conveniência produtiva, ou retarda a assinatura da carteira. Como utilizar esse parâmetro, se as contratações nas próprias empresas se caracterizam por curtos períodos?

A informalidade decorrente das subcontratações gera tensões constantes entre trabalhadores e patrões, contudo, quase sempre, são os trabalhadores que se encontram em desvantagem, pois, como admitiu este trabalhador:

Tem hora que a gente não tem a quem recorrer, né? Se a gente bota advogado é uma demora também pra poder conseguir esse direito que a gente tem por direito, por lei. É uma demora. Então é dessa maneira.

Muitas eu deixei pra lá. Mas, uma eu tive que colocar na justiça. Não citando nome né..? Mas eu tive que colocar porque não teve acordo com esse gato, aí foi o jeito eu colocar. Através de mim e de meu cunhado... eu nem queria, mas, através de meu cunhado, eles me chamaram, e eu entrei em acordo mais eles, e nós fomos no Ministério do Trabalho. Mas, até agora não saiu nada... Tá lá com o juiz (informação verbal) ${ }^{19}$ (Grifos nossos).

O medo de retaliações, a demora na tramitação dos processos judiciais, as condições materiais dos trabalhadores, entre outras situações, garantem a permanência da informalidade nos canteiros de obras, e os trabalhadores seguem duramente penalizados, apesar do crescimento das reclamações trabalhistas ou da fiscalização sindical e jurídica.

\section{Hierarquia e poder nos canteiros de obras: quem é chefe e quem é cachimbo?}

Com a intensa divisão do trabalho na construção civil habitacional, observa-se a constituição de diferentes atribuições para os trabalhadores, mesmo que tenham sido contratados formalmente para desempenhar uma mesma função. Essa fragmentação acaba por produzir relações de poder sustentadas por uma hierarquia entre os trabalhadores nos canteiros de obra. Nas entrevistas com os trabalhadores, essa hierarquia foi bastante salientada e, apesar de percebê-la entre as diferentes funções, ela também se manifesta no interior de uma mesma função. Assim, foi possível identificar tensões em várias combinações: entre pedreiros e serventes, entre pedreiros e mestres de obra, entre pedreiros, entre serventes etc.

O relato de um pedreiro sobre um conflito com um colega pedreiro ilustra esse embate:

Um dia eu cheguei no trabai, e um colega meu, também pedreiro, que trabaiava junto comigo, começou a prestá assunto no meu serviço. E falô: óia,

\footnotetext{
${ }^{19}$ Entrevista concedida por um trabalhador da construção civil. Entrevista gravada por Miriam Cléa Coelho Almeida em $20 / 11 / 2015$
}

Geopauta, Vitória da Conquista, ISSN: 2594-5033, V. 4, n.3, 2020, p.(227-254) http://periodicos2.uesb.br/index.php/geo, 
pro que tu não fais assim, assim... Tu tá fazeno errado. Aí, eu disse pra ele, "não moço, você é que tá errado, eu tô acustumado a fazer assim. Assim é que é o certo". Aí, eu achei estranho porque ele não era o mestre, nem o encarregado. Aí, no dia seguinte, fui conversar com um encarregado da obra e falei disso que aconteceu. Aí, ele me disse que meu colega tava recebendo por fora, que o mestre de obra tava pagano ele para fiscalizar a obra por ele. E, se alguma coisa saísse errada, o mestre de obra ia brigar com ele. Quando eu sube disso, eu fui questionar por que nois tinha o mesmo registro na carteira, e ele tava ganhano mais. Isso não tava certo, não. Mas, aí, aconteceu um problema lá, e o mestre de obras vei pra cima dele, colocano a culpa nele de um defeito que discubriro lá. O pobre levou fumo. Eu falei pra ele que ele tava seno era cachimbo...(Informação verbal) ${ }^{20}$

Já o destaque de um episódio ocorrido entre um mestre de obras e um engenheiro revela os embates e as disputas entre os trabalhadores com funções diferentes:

[...] um dia um engenheiro me falou assim: Óia, mais vale a prática de que, como se diz, de conhecer a gramática. Nós somos um engenheiro, um engenheiro novo, quando eles chega, ele não entende da prática, ele tem a teoria, mas a prática num tem. Quem tem a prática é vocês, que trabalha. Então, o pedreiro tem que ter contato com o engenheiro pra ele dá a teoria, e ocê com a prática. Vale muito. Mas ele me falou assim: engenheiro novo não aceita isso não... Engenheiro novo que chegou lá e formou recente não aceita isso aí, não... Até eu conversando com ele que um dia, até numa obra até de um engenheiro também, aí tinha um negócio lá que ele tava assim mêi... Ai eu falei "Ô dotô, eu posso dar uma sugestão aqui?" E ele falou: "O engenheiro aqui sou eu! Aí eu conversando com um engenheiro que já era velho, ele falou: "Pois é, o erro de hoje é esse que o engenheiro novo não aceita sugestão do encarregado da obra, ou seja, o mestre, né?. Ele não aceita não, foi o que ele falou pra você: 'o engenheiro daqui sou eu!'. Se é assim, faça a obra”(Informação verbal) ${ }^{21}$.

É na divisão do trabalho que se encontra a gênese desse processo. A fragmentação do trabalho e dos trabalhadores nos canteiros de obras intensifica o estranhamento. $\mathrm{O}$ trabalhador não reconhece o seu produto, não se reconhece no processo de trabalho, não se reconhece como ser e não reconhece uns aos outros. Essa realidade, embora desastrosa para os trabalhadores, é fundamental para a acumulação do capital.

O controle e a dominação dos corpos por parte daqueles trabalhadores que detêm o poder de mando e, portanto, representam o capital, incitam trabalhadores contra trabalhadores, acirrando a competição e as disputas, distanciando-os do reconhecimento de si como classe e esfacelando a memória.

\section{Luta e resistência dos trabalhadores da construção civil habitacional}

\footnotetext{
${ }^{20}$ Ibidem

${ }^{21}$ Idem
}

Geopauta, Vitória da Conquista, ISSN: 2594-5033, V. 4, n.3, 2020, p.(227-254) http://periodicos2.uesb.br/index.php/geo, 
A fragmentação do trabalho, as diferenças salariais e as relações de poder marcam as memórias dos trabalhadores da construção civil habitacional e levantam questões importantes: como pensar em classe, consciência de classe e em luta de classes diante da realidade concreta? Ou melhor, como falar em classe com uma categoria de trabalhadores tão internamente dividida? É possível encontrar uma unidade que aglutine essa diversidade e seja capaz de construir uma identidade de classe? É possível falar em consciência de classe nesses termos? Como tratar dessas questões tendo os trabalhadores autônomos como parâmetro? Obviamente, os limites deste estudo não permitem aprofundar essas questões, apenas sinalizá-las como possibilidades para futuras investigações.

Entretanto, não se pode omitir que, na construção civil habitacional, em decorrência da agudização da divisão de trabalho, a forma tradicional de trabalho executada em parceria entre o pedreiro e o servente, na qual o pedreiro realizava todas as etapas da construção, ou seja, do alicerce ao telhado com o auxílio do servente, transformou-se em uma complexa e polissêmica organização de trabalho, fragmentada em diversas especializações e relações, cujo objetivo é dar maior celeridade na produção e circulação da mercadoria e, ainda, ampliar o processo de alienação dos trabalhadores.

A presença de engenheiros, pedreiros, encanadores, eletricistas, gesseiros, vidraceiros, carpinteiros, encarregados, apontadores, armadores, serventes, mestre de obras, entre outros, nas obras da construção civil habitacional, em canteiros de obras de grande, médio e ou pequeno portes, empreendidas por empresas ou por particulares, por trabalhadores assalariados (vinculados à própria empresa ou terceirizados) ou autônomos (sem carteira assinada ou por conta-própria), atestam essa polissemia e multiface do trabalho na construção civil habitacional.

Contudo, não se pode negar que essa intensa divisão do trabalho que impulsiona a acumulação capitalista produz um efeito devastador para os trabalhadores não apenas no espaço de trabalho, mas, também, no espaço de viver, como se verá na próxima seção. No canteiro de obras, os interesses se chocam, as relações de poder e dominação se instalam entre os próprios trabalhadores. As pautas de reivindicações não se convergem, e a luta se enfraquece. Enquanto os trabalhadores digladiam-se, o capital se reproduz livremente à custa da exploração e da precarização do trabalho.

$\mathrm{Na}$ construção civil habitacional, entre os trabalhadores assalariados entrevistados, $50 \%$ afirmaram ser filiados ao sindicato, $47 \%$ não eram filiados, e 3\% não souberam responder. 
Entre os que eram filiados, $68 \%$ justificaram a filiação por ser uma exigência da empresa, $11 \%$, porque facilitava a reivindicação de direitos, $11 \%$, porque viam vantagem, mas não indicaram qual a vantagem, 5\% acreditavam que, com isso, teriam mais segurança no trabalho, e 5\% não souberam responder.

Entretanto, não se pode concluir que "[...] a ausência de consciência de classe no sentido moderno não implica a ausência de classes e de conflitos de classe" (HOBSBAWM, 2008, p. 41). Prova disso é que, em março de 2014, os trabalhadores da construção civil conseguiram fazer a primeira greve do interior, considerada a mais expressiva da categoria em termos de adesão e duração.

Segundo o representante do Sindicato dos Trabalhadores na Indústria da Construção e da Madeira no Estado da Bahia (Sintracom-VC) ${ }^{22}$, a greve conseguiu atingir $95 \%$ dos canteiros de obras em toda a Bahia. Entre as reivindicações dos trabalhadores, estavam o reajuste do salário e da cesta básica e a correção do piso salarial cadastrista. No levantamento do Sintracom-VC, o movimento paredista contou com uma adesão de, aproximadamente, três mil trabalhadores da construção civil em Vitória da Conquista.

Essa greve foi muito comemorada pelos trabalhadores da construção civil em Vitória da Conquista, pois, até 2003, não existia sindicato que os representasse. Em 2004, por força da mobilização dos trabalhadores, foi criado o Sintracom-VC, com o objetivo de lutar por melhores condições de trabalho e salário.

Para Harvey (1982, pp. 34-35).), isso se explica porque,

Embora o capital possa dominar e impor sobre nós um sentido de natureza humana predominantemente capitalista, as resistências estarão sempre presentes e as tensões internas dentro da ordem capitalista - entre apropriação privada e a produção socializada, entre individualismo e interpendência social - são tão dramáticas que cada um de nós internaliza, em nossa conduta atual, um verdadeiro redemoinho de esperanças e temores.

O sindicato contava em 2015 com aproximadamente 2.500 filiados, embora esse número seja muito variável em decorrência da alta rotatividade dos trabalhadores nos postos de trabalho. As bandeiras de luta do sindicato, conforme declaração do presidente, são: redução da jornada de trabalho para 40 horas sem redução de salário; fim do fator previdenciário; adicional de periculosidade; aposentadoria aos 30 anos de contribuição; mais segurança e saúde no trabalho; e melhores salários.

\footnotetext{
${ }^{22}$ Extraído de http://www.blogdoanderson.com/2014/03/28/trabalhadores-da-construcao-civil-continuam-em-greve/ 
Desde a criação do Sintracom de Vitória da Conquista, segundo o presidente, as principais conquistas alcançadas por meio das ações do sindicato foram:

[...] estabelecer um piso salarial acima do mínimo nacional para os ajudantes que são os trabalhadores com menor remuneração do setor; fornecimento gratuito de almoço; café da manhã; cesta básica; aviso prévio "sempre" indenizado; fardamento; horas extras de até $110 \%$; um dia de feriado para o Trabalhador da Construção, entre outras (informação verbal) ${ }^{23}$.

Além do sindicato, os trabalhadores também buscam o Ministério do Trabalho para resolver demandas trabalhistas. Mesmo assim, a alternativa preferida dos trabalhadores, tanto assalariados, quanto autônomos, é procurar resolver os problemas trabalhistas com a empresa ou o contratante. Muitos trabalhadores, mesmo pagando a contribuição sindical, declararam não saber se são filiados ou a qual Sindicato estão filiados. Em vários momentos das entrevistas, os trabalhadores salientavam com muita satisfação o fato de nunca ter levado nenhum patrão à justiça. Esse comportamento é compreensível se se levar em consideração o que vem se consolidando na memória: "trabalhador bom é aquele que não leva patrão na justiça", ou “pedreiro bom é aquele que não bota o patrão no pau”. Esse "pacto" é a garantia do próximo trabalho, da próxima empreita, da próxima empresa, ou melhor, é garantia de sobrevivência.

A fragmentação dos trabalhadores com as diferentes formas flexíveis de contratação e a divisão do trabalho na construção civil habitacional têm dificultado a resistência e deixado os trabalhadores em uma situação cada vez mais vulneráveis às práticas precárias de trabalho.

Entretanto, a heterogeneidade, a fragmentação e a complexidade não devem ser um impeditivo para a organização dos trabalhadores, sobretudo, num momento em que é fundamental reforçar o plano de lutas e resistência. Além disso, Lukács (2003) já advertia que não é da soma dos pensamentos ou dos sentimentos individuais que emerge a consciência de classe. Ao contrário, a consciência de classe é um produto social, portanto está acima das percepções individuais. Ademais, por ser produto social, na classe não há perfeita homogeneidade (HOBSBAWM, 2008). Nesse sentido, é essencial considerar a complexidade social, as estratificações, entre outros, inerentes às classes. Isso pode explicar como trabalhadores que defendem interesses distintos conseguem se perceber como classe e, mais que isso, ter consciência de si e empreender as suas lutas.

\section{Considerações finais}

\footnotetext{
${ }^{23}$ Entrevista concedida pelo Presidente do Sintracom - VC. Entrevista gravada por Miriam Cléa Coelho Almeida em $20 / 02 / 2015$
}

Geopauta, Vitória da Conquista, ISSN: 2594-5033, V. 4, n.3, 2020, p.(227-254) http://periodicos2.uesb.br/index.php/geo, 
A análise das memórias e do processo de trabalho na construção civil habitacional em Vitória da Conquista - BA revela as condições objetivas criadas pelo capital para garantir a extração do lucro. O uso intenso da força de trabalho é marcado por estratégias tradicionais a masculinização, a baixa escolarização, a baixa remuneração, a extensa jornada de trabalho, a falta de segurança - e por mecanismos viabilizados pela acumulação flexível - a fragmentação, a rotatividade, a terceirização e a informalidade.

Essas objetivações são produzidas ao tempo em que se processam as subjetivações que garantirão ora a reafirmação das condições objetivas, ora forçarão a sua ruptura. São as tensões e os conflitos nos canteiros de obra, marcados por "cimento e lágrimas", que fazem emergir o plano de lutas e resistência dos trabalhadores e trabalhadoras da construção civil habitacional em Vitória da Conquista e sinalizam para futuras objetivações, num movimento permanente circunscrito na relação contraditória capital-trabalho.

\section{Referências}

ALMEIDA, M. C.C. Memória, trabalho e território: o processo de trabalho na construção civil na cidade de Vitória da Conquista - BA. 202f. Tese (Doutorado em Memória Linguagem e Sociedade), Universidade Estadual do Sudoeste da Bahia, Vitória da Conquista, BA, 2017.

ANTUNES, R. O caráter polissêmico e multifacetado do trabalho. Revista Trabalho, Educação e Saúde, v. 1, n. 2, p.53-6, 2003.

BRAVERMAN, H. Trabalho e capital monopolista. A degradação do trabalho no século XX. 3. ed. Rio de Janeiro, LTC, 1987. Tradução: Nathanael C. Caixeiro.

FRIGOTTO, G; CIAVATTA, M.; RAMOS, M. A educação de trabalhadores no Brasil contemporâneo: um direito que não se completa. In: Germinal: Marxismo e Educação em Debate, Salvador, v. 6, n. 2, p. 65-76, dez. 2014. Disponível em:

http://www.portalseer.ufba.br/index.php/revistagerminal/article/viewFile/13088/9294. Acesso em: $25 / 11 / 2015$.

GAUDEMAR, J. P. de. Mobilidade do trabalho e acumulação do capital. Lisboa: Estampa, 1977.

HARVEY, D. O trabalho, o capital e o conflito de classes em torno do ambiente construído nas sociedades capitalistas avançadas. In: Revista Espaço e Debates. São Paulo: Cortez, n. 6, jun./set., 1982. Tradução: Flávio Villaça.

HARVEY, D. Condição pós-moderna. 9. ed. São Paulo: Loyola, 2000.

HOBSBAWM, E. J. Mundos do trabalho. Novos estudos sobre história operária. 5. ed. São Paulo: Paz e Terra, 2008. Tradução: Waldea Barcellos e Sandra Bedran. 
INSTITUTO BRASILEIRO DE GEOGRAFIA E ESTATÍSTICA (IBGE). Censo demográfico do Brasil - Bahia, 2010.

KUENZER, A. Z. Pedagogia da fábrica. As relações de produção e a educação do trabalhador. 4. ed. São Paulo: Cortez, 1995.

KUENZER, A. Z. As relações entre conhecimento tácito e conhecimento científico a partir da base microeletrônica: primeiras aproximações. Educar. Curitiba-PR: Editora UFPR, Especial, p. 43-69, 2003.

LUKÁCS, G. História e consciência de classe. Estudos sobre a dialética marxista. São Paulo: Martins Fontes, 2003. Tradução: Rodnei Nascimento. Revisão da tradução: Karina Jannini.

MARTINS, J. de S. Capitalismo e tradicionalismo. São Paulo: Biblioteca Pioneira de Ciências Sociais, 1975.

MARX, K. O capital: crítica da economia política. V. I, 2. ed., São Paulo: Nova Cultural, 1985, (V. I) (Coleção os Economistas).

MARX, K. Manuscritos econômicos e filosóficos. São Paulo: Boitempo, 2010. Tradução: Jesus Ranieri.

POLLAK, M. Memória, esquecimento, silêncio. In: Estudos Históricos. Rio de Janeiro, vol. 2, n. 3, 1989, p. 3-15. 